\title{
Cost Benefit Analysis and Data Analytics for Renewable Energy and Electrical Energy Storage
}

\author{
Chun Sing Lai ${ }^{1}$, Xuecong Li $^{2}$, Giorgio Locatelli ${ }^{3}$, Loi Lei Lai ${ }^{4}$ \\ 1,2,4 Department of Electrical Engineering, School of Automation, Guangdong University of Technology, \\ Guangzhou 510006, China \\ ${ }^{1,3}$ School of Civil Engineering, Faculty of Engineering, University of Leeds, Leeds, LS2 9JT, U.K. \\ ${ }^{1}$ c.s.lai@leeds.ac.uk²leexuecong@163.com³․․locatelli@leeds.ac.uk¹.1.lai@ieee.org
}

\begin{abstract}
To accommodate with the global increase in the deployment of solar photovoltaic (PV) and energy storage system (ESS), a deterministic approach for sizing PV and ESS with anaerobic digestion biogas power plant; to meet a load demand will be presented in this plenary session. This aim is to maximize the sizing of PV to increase the security of energy supply. Energy economics for ESS will be a focus. Case study based on real-life data will be used to demonstrate the validity of the new approach.
\end{abstract}

\section{INTRODUCTION}

There have been many discussions and studies under different scenarios on energy generation fully based on $100 \%$ renewables in 2050 . Some of the most possible candidates are wind and solar [1,2]. In this paper, solar is the focus. Solar energy is a clean and sustainable energy resource. The solar potential $\left(50 * 10^{21} \mathrm{~J}\right)$ based on the availability land area greatly exceeds the humankind energy consumption $\left(0.376 * 10^{21} \mathrm{~J}\right)$ as of 2012 [3]. With zero fuel-cost, it is one of the most highly anticipated energy for electricity production. However, several critical issues need to be addressed for a reliable and economical system. Solar is a diurnal and intermittent source of energy. The irradiance is related to the atmospheric and weather conditions [4].

Large amount of solar data is required to perform solar energy system planning and operations [5]. To handle the big data, data analysis based on simple compiling such as correlation and analysing the data is not adequate. Data analytics is the study and implementation of effective algorithms and methodologies for data analysis.

\section{DATA ANALYTICS FOR SOLAR}

Clearness index $(\mathrm{CI})$ is a useful indicator for solar resource [3-7]. It effectively displays the expected resource availability and the underlying weather perturbation. A CI of one indicates the expected maximum potential is received, whereas zero indicates a completely block of solar irradiance. A useful clustering algorithm for daily CI profile is presented in [7] for solar PV system planning. Fuzzy C-Means with Dynamic Time Warping distance is an effective tool to extract patterns from the CI data set. Fig. 1(a) depicts the clearness index for four seasons with each colour represents a day. It can be seen that Winter has the most clear days. Fig. 1(b) shows the clustering results for the Summer data set. The black line is the average with the blue and red lines are the plus one and minus one standard deviation. Each cluster is distinctive and shows solar variation for a day. To study the usefulness of clustering for hybrid energy planning, the clustering method was successfully applied to a hybrid energy system sizing problem in [8]. The system sizing problem and techno-economic analysis will be explained in the remaining paper.

Here, the optimal sizing is defined as the sizing to achieve the minimal levelized cost of electricity (LCOE). For the stand-alone hybrid renewable power system, this is achieved by determining the balance of energy supply and demand. When the system is oversized (surplus energy is more than the deficit energy), energy wastage will occur and LCOE will increase. The undersized system will cause the energy imbalance issue and lead to a reduced energy security.

Energy security is defined as "consistent availability of sufficient energy in various forms at affordable prices" [9]. International Energy Agency (IEA) defines energy security as "the uninterrupted availability of energy sources at an affordable price" [10]. Hence, energy security considered here is the availability. The risk with undersized or reduced availability will be the increasing trigger of power outage and unintentional voltage drop in the hybrid system.
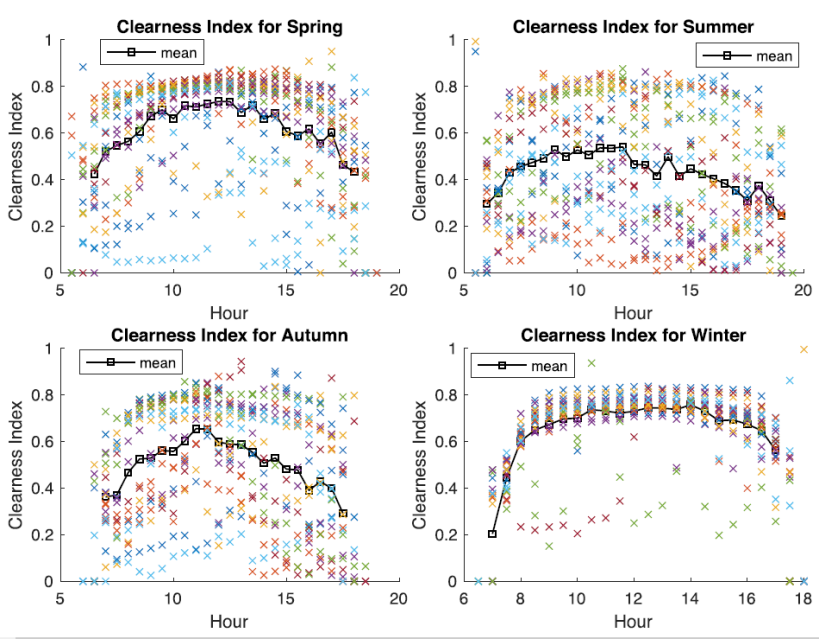

(a) 

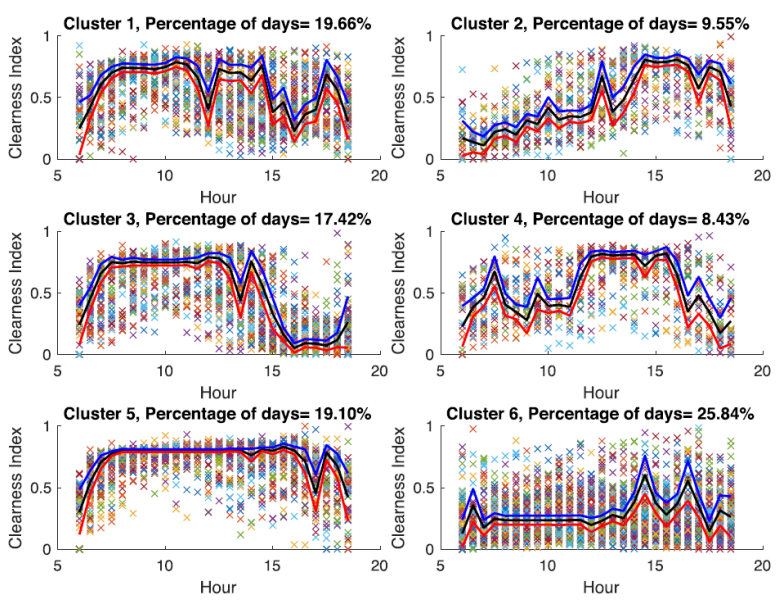

(b)

Fig. 1. a) CI for four seasons b) clustering results for Summer [5].

\section{SYSTEM SIZING PROBLEM}

Since the marginal cost for PV is close to zero, AD has a higher operating cost, i.e., fuel cost and hence it is less affordable and reduces the security of supply. Therefore, it is ideally to maximize the use of PV to meet deficit energy. A security of supply index is defined here, which presents the percentage of days that the deficit energy will be met. Ideally, this index should be maximized. This is defined in Equation (1) as follows:

Security of supply $=\frac{\text { Number of days for } E_{\text {Surplus }} \geq E_{\text {Deficit }}}{\text { Total number of days }} * 100$

Fig. 2(a) presents the required panel areas for each day to achieve the system energy balance, i.e., $E_{\text {Surplus }}=E_{\text {Deficit }}$ with EES. To understand the boxplot results, a histogram is presented in Fig. 2(b) to give the distribution of the solar farm rated capacity with respect to the number of days.
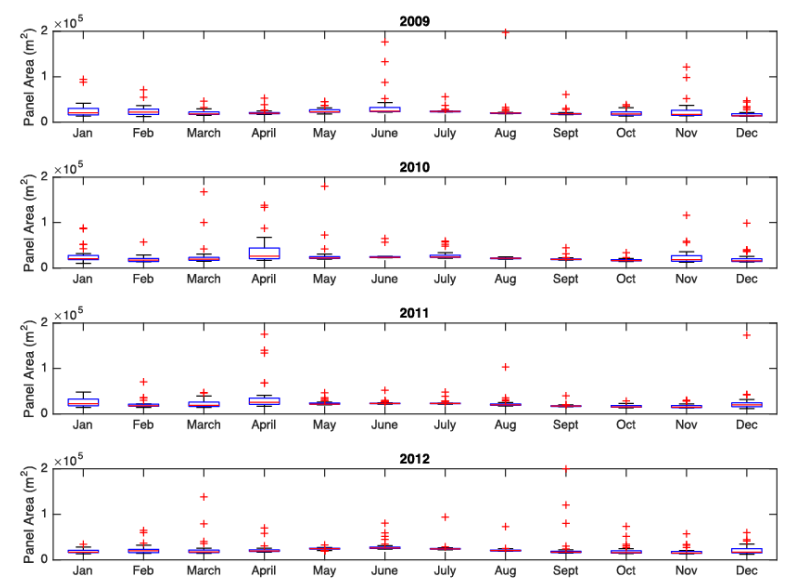

(a)

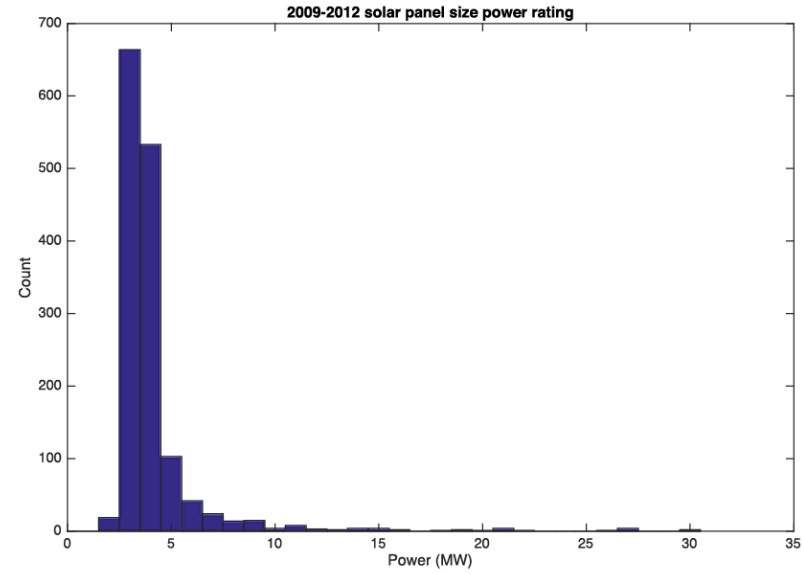

(b)

Fig. 2. a) Panel sizing results histogram b) histogram for results [6].

\section{COST BENEFIT ANALYSIS}

Cost benefit analysis concerns with comparing the benefits and costs of an investment [11]. For engineering systems, techno-economic studies are commonly performed for cost benefit analysis, to examine if and how an investment, e.g. include storage can be a sound decision [12-15].

The economics for storage is attracting an increased attention. It is a complicated matter as storage is not a form of generation. The term levelized cost of storage (LCOS) was explored in [16] which is solely used for comparing storage technologies. The equation is of similar nature to LCOE. As the energy stored in EES comes from a generator, the term levelized cost of delivery (LCOD) is proposed to accommodate the generation cost. The LCOD is given as follows:

$\mathrm{LCOD}=\frac{\sum_{t=0}^{n} \frac{C_{\mathrm{in}_{t}}}{(1+r)^{t}}}{\eta \sum_{t=0}^{n} \frac{E_{\mathrm{in}_{t}}}{(1+r)^{t}}}+\frac{\sum_{t=0}^{n} \frac{C_{\mathrm{ESS}_{t}}}{(1+r)^{t}}}{\eta \sum_{t=0}^{n} \frac{E_{\mathrm{in}_{t}}}{(1+r)^{t}}}$

$C_{\mathrm{in}_{t}}$ is the fixed and variable costs for generating the electricity to be stored in EES (\$), $C_{\mathrm{ESS}}$ is the fixed and variable cost of EES $(\$), E_{\mathrm{in}_{t}}(\mathrm{kWh})$ is the energy input to EES, $\eta$ is the round-trip efficiency (\%), $r$ is the discount rate $(\%), t$ is the year, $n$ is the system lifetime in years.

\section{FUTURE WORK AND CONCLUSIONS}

This plenary paper presents a data analytics method for solar energy. This is applied to a solar hybrid energy system sizing problem. Then, the economics for storage is discussed with a focus on levelized cost of electricity.

Currently, most work focus on the economic studies for the hybrid energy system. Financing models will be important to realize how stakeholders of the energy system will influence the system economics. Energy system models for storage and renewables will need to effectively and efficiently accommodating the intermittent generation, and this needs to be reflected in the economic and finance models. 


\section{ACKNOWLEDGMENTS}

The authors would like to express their gratitude to The IET $11^{\text {th }}$ International Conference on Advances in Power System Control, Operation and Management (IET APSCOM 2018) Organising Committee for the invitation to present this plenary paper. This work is supported by EPSRC Grant "GIES: Generation Integrated Energy Storage: A Paradigm Shift” (EP/P022049/1); Department of Finance and Education of Guangdong Province 2016[202]: Key Discipline Construction Program, China; and Education Department of Guangdong Province: New and Integrated Energy System Theory and Technology Research Group [Project Number 2016KCXTD022].

\section{REFERENCES}

[1] D. X. Wang, X. D. Gao, K. Meng, J. Qiu, L. L. Lai and S. Gao, "Utilization of kinetic energy from wind turbine for grid connections: A review paper," IET Renewable Power Generation 2018, 12 (6): pp. 615-624.

[2] D. Q. Wu, J. H. Yang, T. F. Chan, C. S. Lai, X. C. Li, B. P. Yan, L. L. Lai, D. X. Wang, X. D. Gao and K. Meng, "Axial-flux permanent-magnet synchronous generator with coreless armature and non-integral coil-pole ratio," IET Renewable Power Generation. (Accepted)

[3] C. S. Lai, Y. Jia, L. L. Lai, Z. Xu, M. D. McCulloch, and K. P. Wong, "A comprehensive review on large-scale photovoltaic system with applications of electrical energy storage," Renewable and Sustainable Energy Reviews, vol. 78, pp. 439-451, 2017.

[4] C. S. Lai, X. Li, L. L. Lai, and M. D. McCulloch, "Daily clearness index profiles and weather conditions studies for photovoltaic systems," Energy Procedia, vol. 142, pp. 77-82, 2017.

[5] C. S. Lai, F. Xu, Y. Tao, W. W. Y. Ng, Y. Jia, H. Yuan, C. Huang, L. L. Lai, Z. Xu and G. Locatelli, "A robust correlation analysis framework for imbalanced and dichotomous data with uncertainty," Information Sciences, vol. 470, pp. 58-77, 2019.

[6] H. Khorasanizadeh, K. Mohammadi, and N. Goudarzi, "Prediction of horizontal diffuse solar radiation using clearness index based empirical models; A case study," International Journal of Hydrogen Energy, vol. 41, pp. 21888-21898, 2016.

[7] C. S. Lai, Y. Jia, M. D. McCulloch, and Z. Xu, "Daily clearness index profiles cluster analysis for photovoltaic system," IEEE Transactions on Industrial Informatics, vol. 13, pp. 2322-2332, 2017.

[8] C. S. Lai and M. D. McCulloch, "Sizing of stand-alone solar PV and storage system with anaerobic digestion biogas power plants," IEEE Transactions on Industrial Electronics, vol. 64, no. 3, pp. 2112-2121, 2017.

[9] M. Asif and T. Muneer, "Energy supply, its demand and security issues for developed and emerging economies," Renewable and Sustainable Energy Reviews, vol. 11, no. 7, pp. 1388-1413, 2007.

[10] "Energy security," International Energy Agency, [Online]. Available: https://www.iea.org/topics/energysecurity/ [Accessed: 03.08.2018].

[11] S. N. Ravadanegh, N. Jahanyari, A. Amini, and N. Taghizadeghan, "Smart distribution grid multistage expansion planning under load forecasting uncertainty," IET Generation, Transmission \& Distribution, vol. 10, no. 5, pp. 1136-1144, 2016.
[12] G. Locatelli, D. C. Invernizzi, and M. Mancini, "Investment and risk appraisal in energy storage systems: A real options approach," Energy, vol. 104, pp. 114-131, 2016.

[13] G. Locatelli, E. Palerma, and M. Mancini, "Assessing the economics of large Energy Storage Plants with an optimisation methodology," Energy, vol. 83, pp. 15-28, 2015.

[14] S. D. Garvey et al., "On generation-integrated energy storage," Energy Policy, vol. 86, pp. 544-551, 2015.

[15] C. S. Lai, Y. W. Jia, Z. Xu, L. L. Lai, X. C. Li, J. Cao, and M. D. McCulloch, "Levelized cost of electricity for photovoltaic/biogas power plant hybrid system with electrical energy storage degradation costs," Energy Conversion and Management 153 (2017) pp. 34-47.

[16] C. S. Lai and M. D. McCulloch, "Levelized cost of electricity for solar photovoltaic and electrical energy storage," Applied Energy, vol. 190, pp. 191-203, 2017. 